\title{
SPECIAL
}

\author{
Arkadiusz Mężyk • Mariusz Pawlak • Wojciech Klein • \\ Jan Kania
}

\section{Modeling and optimization of resonance characteristics of complex machinery system under dynamic load}

Received: 31 December 2013 / Accepted: 25 June 2014 / Published online: 25 November 2014

(C) The Author(s) 2014. This article is published with open access at Springerlink.com

\begin{abstract}
The paper deals with the optimization of the dynamic characteristics of a complex machinery system. The algorithms for optimization of the dynamic features have been elaborated and applied for a selection of design variables with the aim of minimizing the vibration amplitudes and optimizing the resonance characteristics of the system. A CAD model of the cutting boom of a continuous miner machine has been selected as an example and was adopted in the LS-PrePost command file. This machine has been selected because it is exposed to complex dynamic forces that cause vibrations and shocks. The paper shows the methodology for the optimization of the modal parameters of the complex mechanical system by using the finite elements method. A new objective function was applied and designed for maximization of the differences between eigenfrequencies and excitation peak force frequencies with respect to the total mass of the system. The genetic algorithm method was used to search for the optimal solution. The influence of parameters on the mass and eigenfrequencies is presented as a result of the sensitivity analysis. During the optimization process, a geometrical parameterized model was applied in order to optimize the system. The results of the modal analysis are part of a complex dynamic simulation of the cutter boom which integrates transmission, drives, and cutting head.
\end{abstract}

Keywords Optimization · Modal parameters · Dynamic characteristic $\cdot$ Genetic algorithms · Continuous miner

\section{Introduction}

Reducing the excessive vibrations of a machinery system is a complex problem that, in general, requires numerical simulations to be carried out with the aid of mathematical models of the system under consideration $[1,2]$. The effectiveness of the method used to minimize the vibration level depends on the proper selection of the parameters of the system and is conditioned by the assumed mathematical model of the electromechanical system [3]. Thus, there is a tendency to develop models that take into account more and more factors that

A. Mężyk (ه) • M. Pawlak · W. Klein · J. Kania

Silesian University of Technology, Gliwice, Poland

E-mail: arkadiusz.mezyk@polsl.pl

M. Pawlak

E-mail: mariusz.pawlak@polsl.pl

W. Klein

E-mail: wojciech.klein@polsl.pl

J. Kania

E-mail: jan.kania@polsl.pl 

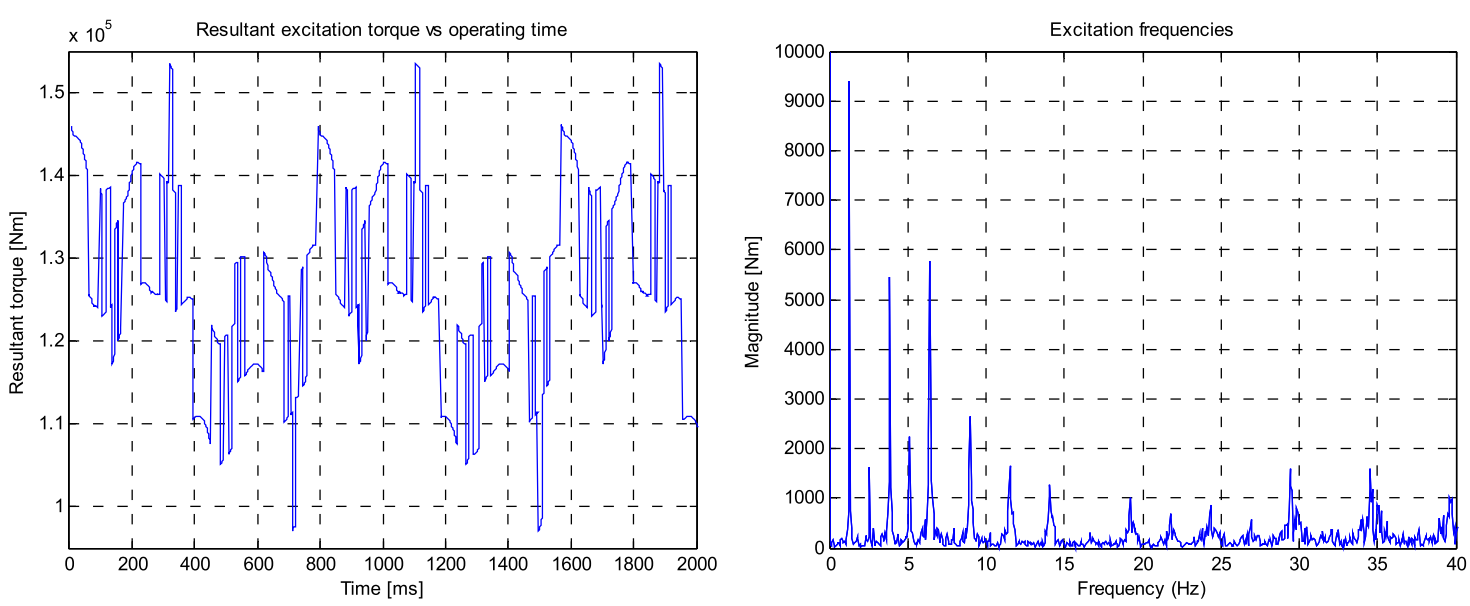

Fig. 1 Signal of resultant excitation torque versus operation time and FFT analysis
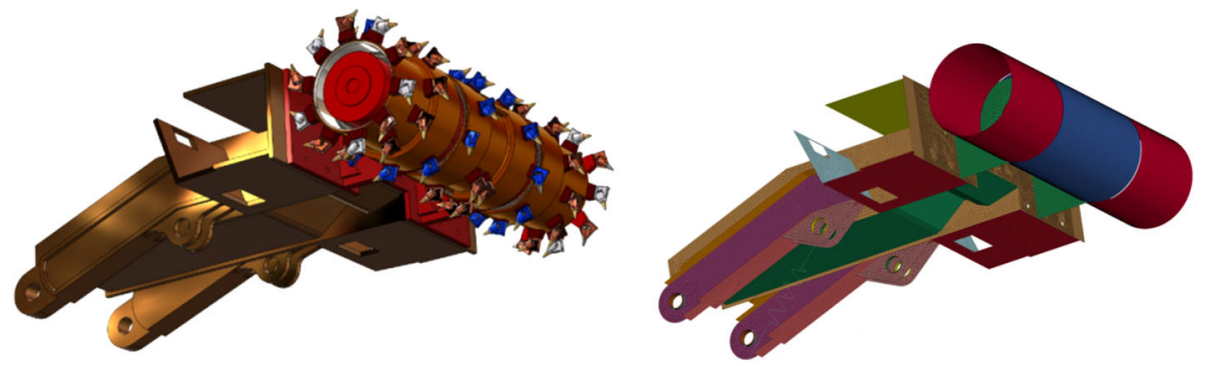

Fig. 2 The CAD and FEM models of the continuous miner boom

determine the phenomena occurring in kinematic pairs of the system, especially in transient states of operation. The mathematical model of the mechanical, electrical, and control systems is used to estimate and optimize the dynamic features of the system of interest [2]. The proper selection of an objective function, which is generally a function of a number of design variables, has a crucial effect on successful optimization [4]. In order to assess the effect of the design variables on the objective function, sensitivity analysis is performed, which effectively supports the optimization process. Thus, the design process should take into consideration the influence of excitation forces and torques.

One of the most important assumptions of the design process is that the overlapping of excitation frequencies and eigenfrequencies of the analyzed system should be avoided because this causes an increase of vibration and shock as a consequence of resonance phenomena.

The cutting boom of a continuous miner machine has been selected as an example of the methodology for the optimization of the modal parameters of a complex mechanical system using the finite elements method. This machine has been selected because it is exposed to complex dynamic forces that cause vibrations and shocks. Figure 1 presents an example of the resultant torque of loads during normal interactions between the cutting head and longwall in the time and frequency domains [5]. To avoid a resonance effect and improve the dynamic characteristics of highly complex systems such as continuous miner booms (Fig. 2), it is possible to modify some of the geometrical parameters without affecting functionality and strength. On the other hand, it is possible to apply different types of passive, semi-active, and active vibration control systems [6]. However, this solution is usually expensive and has a significant influence on the complexity of the whole structure.

\section{Optimization problem}

The optimization problem is focused on finding values of design parameters for which eigenfrequencies of structure are maximally spaced from excitation frequencies. These specified parameters have to be selected 
from geometrical features, and at the same time their values should have a strong influence on the stiffness and mass matrix. The eigenvalue problem for the mechanical system can be defined as:

$$
-\mathrm{K} \cdot \mathrm{x}=\omega^{2} \cdot \mathrm{M} \cdot \mathrm{x}
$$

where $\omega$-eigenfrequency [1/s], $\mathrm{x}$ - eigenvector [m], $\mathrm{K}$-stiffness matrix, and $\mathrm{M}$-mass matrix.

For instance, if we change the thickness of a particular body wall, it will affect the values of specific elements of the stiffness matrix $\mathrm{K}$ and change the mass matrix $\mathrm{M}$. This will reflect on the eigenvalues of the structure, depending on the types of design variables. Thus, the selection of the design variables should be verified using sensitivity analysis [7].

\subsection{Objective function}

If in the optimization of one eigenfrequency there is only one objective function, interpretation of the results is simple [8]. With multiple optimum solutions, different methods are used in engineering design optimization [9].

In the majority of publications, there are common methods of constant weighting of coefficients of the objective functions called the weighted sum method, which represent the relative importance of the objective functions [10-15].

There are articles about other methods based on the normalized normal constraint method based on the Pareto and utopia line $[16,17]$.

In our approach, the target was an optimization process with the objective function formulated as a moving upper limit on the maximum values of the differences between excitation frequencies and neighboring eigenfrequencies. The moving limit value has been calculated as the median of all the considered peaks. The optimization process is similar to the MinMax problem.

A new objective function was elaborated for the maximization of the differences between the eigenfrequencies and closest frequencies of the excitation force component regarding the total mass of the system. The proposed objective function is defined as:

$$
\psi_{k}\left(X_{i}\right)=\operatorname{abs}\left(\left(\frac{\mathrm{VFEP}_{n+1}+\mathrm{VFEP}_{n}}{2}\right)-\mathrm{EF}_{k}\right) \rightarrow \min
$$

where $\psi_{k}$-objective function, VFEP—value of frequency excitation peak, EF-eigenfrequency, $i$-index of design variables, $k$-index of eigenfrequency, and $n$-subsequent excitation peak in specific range.

However, to minimize the total mass of the analyzed structure, a mass factor was added to the objective function as follows:

$$
\psi_{k}\left(X_{i}\right)=\operatorname{abs}\left(\left(\frac{\mathrm{VFEP}_{n+1}+\mathrm{VFEP}_{n}}{2}\right)-\mathrm{EF}_{k}\right) \cdot(W * \mathrm{MASS}) \rightarrow \min
$$

where MASS—-total mass and $W$-weight ratio.

For a multi-eigenfrequency optimization problem, the generalized equation must be considered as a function; the results for various functions were tested (Fig. 3), and the samples are presented as follows:

(a) objective functions $\psi\left(X_{i}\right)=\operatorname{sum}\left(\psi_{k}\left(X_{i}\right)\right) \rightarrow \min$

(b) objective functions $\psi\left(X_{i}\right)=$ mean $\left(\psi_{k}\left(X_{i}\right)\right) \rightarrow \min$

(c) objective functions $\psi\left(X_{i}\right)=\max \left(\psi_{k}\left(X_{i}\right)\right) \rightarrow \min$

(d) objective functions $\psi\left(\boldsymbol{X}_{i}\right)=\boldsymbol{M e}\left(\psi_{\boldsymbol{k}}\left(\boldsymbol{X}_{i}\right)\right) \rightarrow \min$

As can be seen, the best results, which give the smallest values of all the local objective functions at the end of the optimization process, have been obtained for the median function. The median here is regarded as a boundary of the local objective functions, and minimization of the median tends to keep the objective functions of each eigenfrequency at a reasonably low value. 
(a)

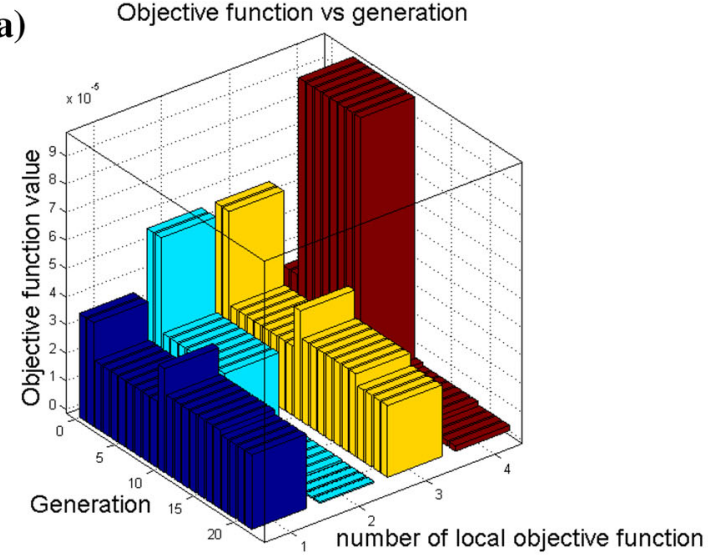

(b)

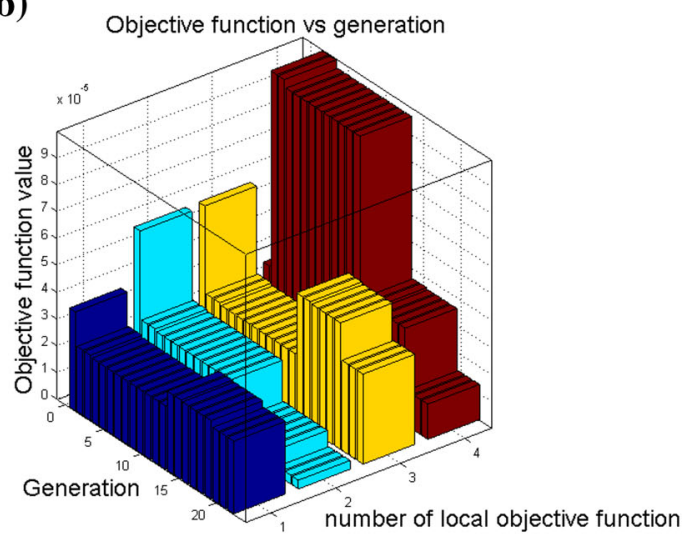

(c)

Objective function vs generation

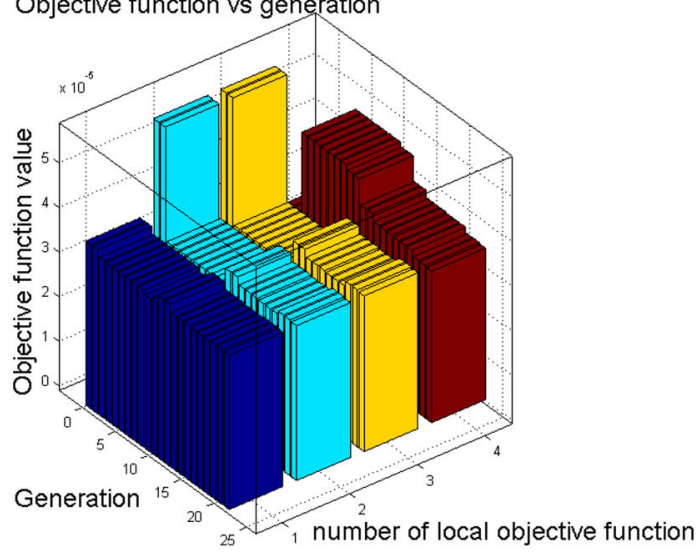

(d)

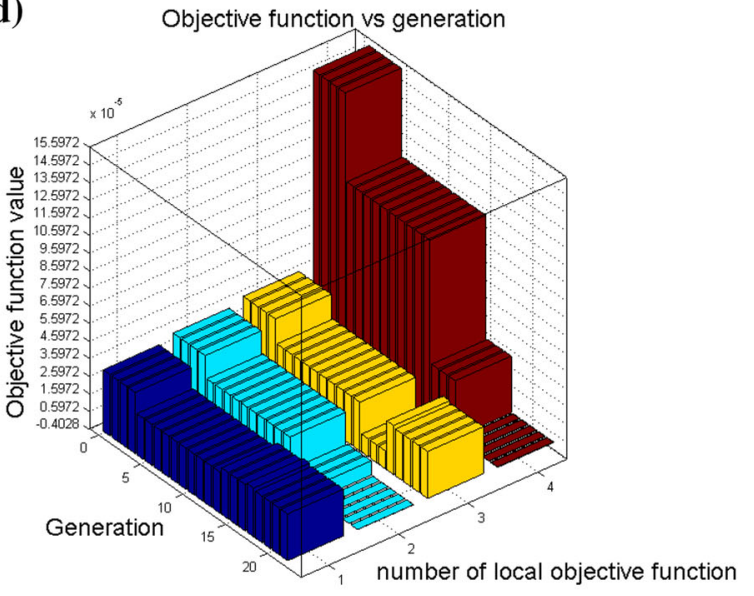

Fig. 3 Minimization by using different types of objective function a Sum of the local objective functions. b Mean value of the local objective functions. c Maximum local objective function. d Median value of the local objective functions

For further simulations, the generalized objective function for the multi-eigenfrequency optimization problem is as follows:

$$
\psi\left(X_{i}\right)=\operatorname{Me}\left(\psi_{k}\left(X_{i}\right)\right) \rightarrow \min
$$

The applied objective function has an explicit form; however, parameters affecting eigenfrequency values are of an implicit character and result from the mathematical model of the complex mechanical system prepared using the FEM formalism.

Due to the application of a generalized description, it is possible to consider the problem of structure optimization over a wide range of excitation frequencies and an increasing number of eigenfrequencies. However, with the aim of showing the applied methodology of action in this paper, the simulation was limited to the fifth eigenfrequency in the excitation frequency gap from 8 to $40 \mathrm{~Hz}$.

\subsection{Optimization process test}

The optimization process for a very complicated structure and many variables requires the use of timeconsuming methods. In order to check the methodology and performance of the proposed objective function, a genetic algorithm optimization process for a simple supported beam model has been performed (Fig. 4) [18-20].

The eigenfrequencies of the simply supported beam are described by the following equation:

$$
\omega=\frac{k^{2} \cdot \pi^{2}}{l^{2}} \cdot \sqrt{\frac{E \cdot b \cdot h^{3}}{\mu \cdot 12}}
$$




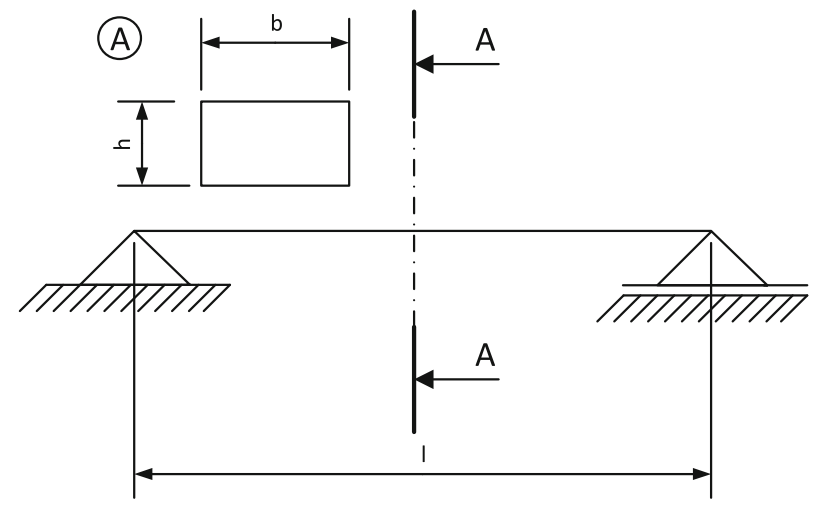

Fig. 4 The simply supported beam of a square cross-section example
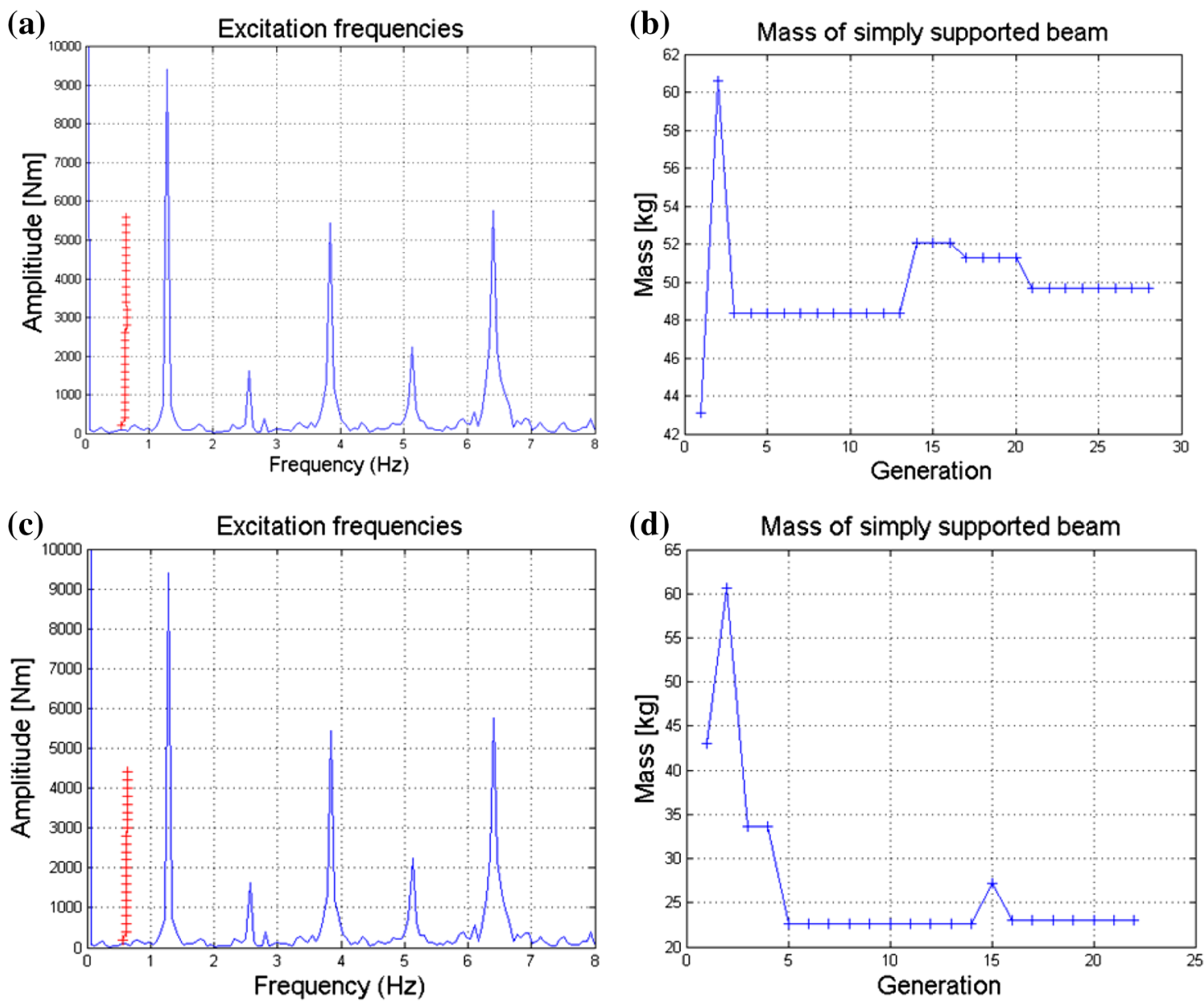

Fig. 5 The results of optimization for one eigenfrequency: $\mathbf{a}$ and $\mathbf{b}$ results without mass factor; $\mathbf{c}$ and $\mathbf{d}$ results with mass factor

where $\omega$-eigenfrequency [1/s], $E$-Young's modulus [Pa], $b$-thickness of beam $\left[\mathrm{m}^{4}\right], u$-linear density $[\mathrm{kg} / \mathrm{m}], k$-index of eigenfrequency value (natural number), and $l$-beam length $[\mathrm{m}]$

The test of optimization was performed for the range from the first to the third eigenfrequency; the eigenfrequencies were optimized according to a predefined objective function. Figures 5, 6, and 7 below present the results of numerical calculation of the genetic algorithm for the considered cases.

In order to compare the results, the same initial conditions were applied in the genetic algorithm method and the random number generator in a MATLAB environment. 

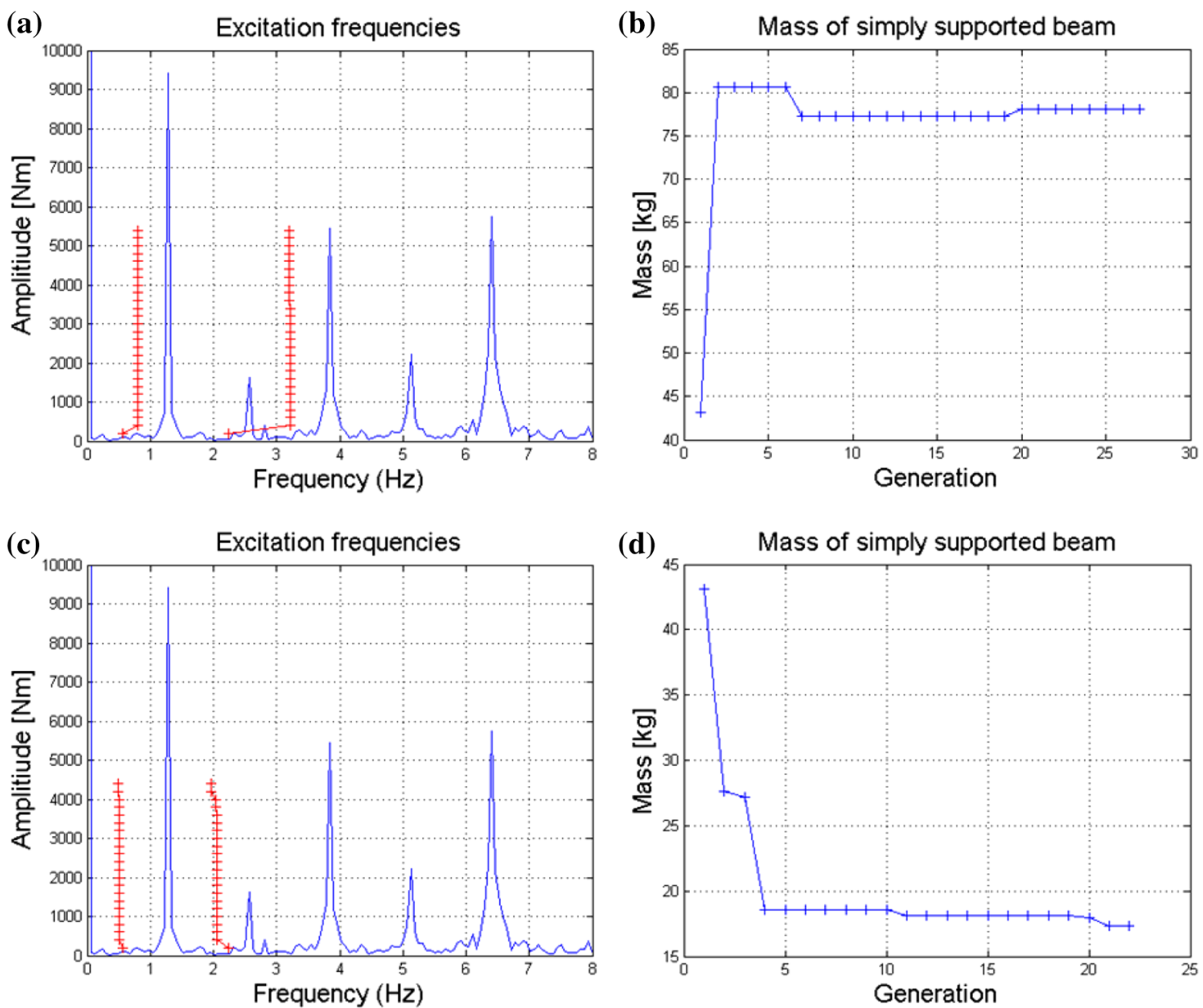

Fig. 6 The results of optimization for two eigenfrequencies: $\mathbf{a}$ and $\mathbf{b}$ results without mass factor; $\mathbf{c}$ and $\mathbf{d}$ results with mass factor

As can be observed, the applied objective function (6) enables proper fitting of eigenfrequencies to the excitation spectrum. The constraints which were imposed (the dimensions of "b" and " $h$ " could change between 0.01 and $0.03 \mathrm{~mm}$ ) for this simple structure allow an appropriate solution to be found. However, narrowing the values of the variables reduces the chance of finding a better solution.

The mass factor in each case allows the total mass of the system to be reduced without undesirable effects on the main task in the objective function. These tests have shown the efficiency of the objective function in minimizing the possibility of resonance occurring for a specific mechanical system.

For more complex models, an important part of the optimization process is the creation of a parametrical model. Models can be prepared in commercial CAD software and converted into LS-DYNA, and the process of optimization can then be controlled by the LS OPT tool implemented in LS-DYNA [21,22].

Optimization can be also conducted using external software, i.e., optiSLang, where information is exchanged between various softwares, for example, LS-PrePost, MATLAB, MADYMO, and LS-DYNA, as presented in the literature [23].

In our work, for managing the optimization process, we use a genetic algorithm and the MATLAB Toolbox. The parametrical model is also defined in the MATLAB environment, where by means of the function file the LS-PrePost command file with specified geometry was created. Discretization of the model is done, and boundary conditions are applied in LS-PrePost, an output file for LS-DYNA simulation is generated and the LS-DYNA calculation executed. The genetic algorithm method requires many iterations of the simulation depending on the size of population and the stopping criteria.

The optimization process for a complex mechatronic system can be done by using a genetic algorithm implemented in MATLAB software and an FEM model of the system. This environment is the core of the optimization method and can be used to manage the data between the finite element environment and the 

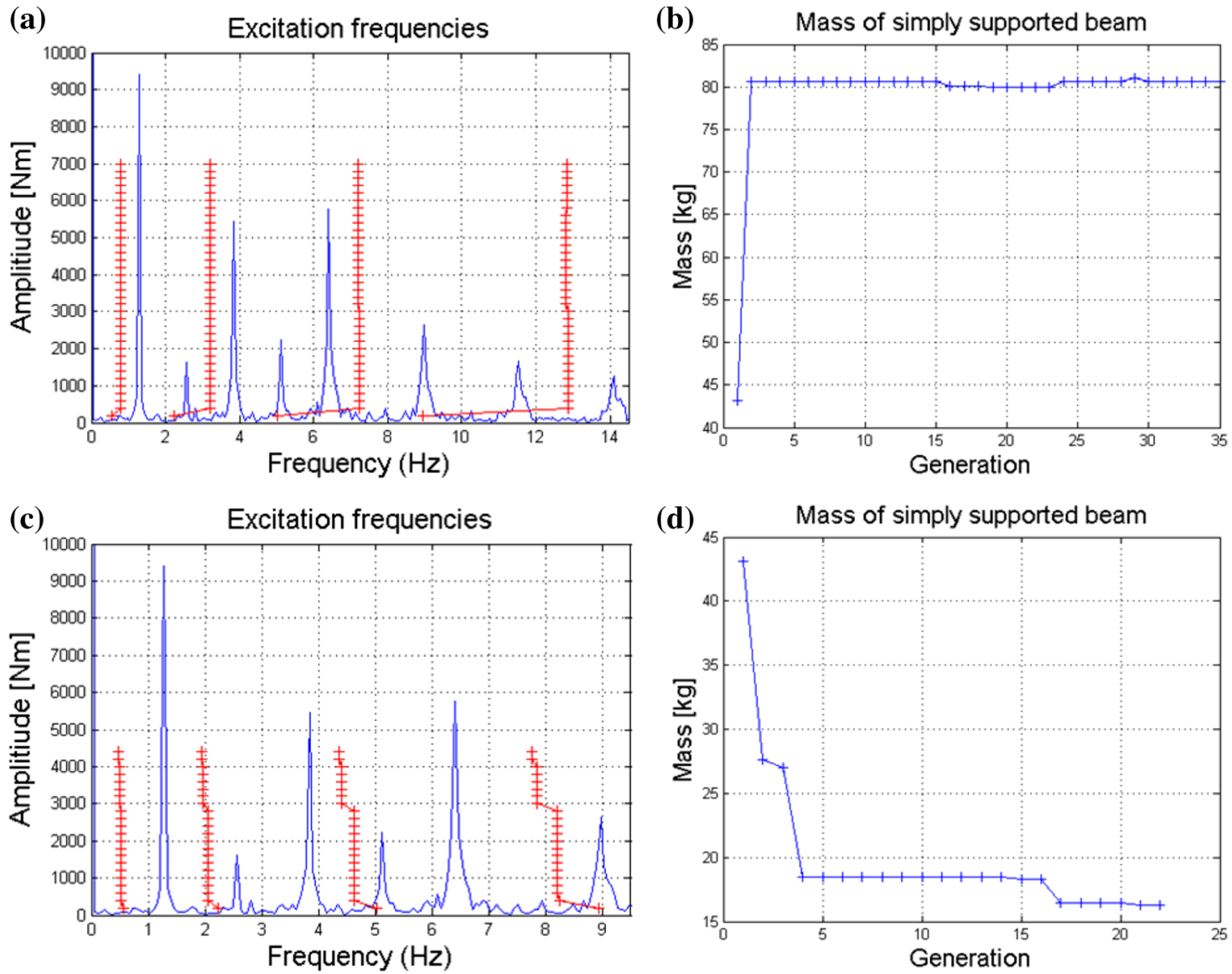

Fig. 7 The results of optimization for four eigenfrequencies: $\mathbf{a}$ and $\mathbf{b}$ results without mass factor; $\mathbf{c}$ and $\mathbf{d}$ results with mass factor

genetic algorithm optimization process. The connection between the FEM environment (LS-DYNA) and the optimization method was made by both the input file and the output file. The MATLAB script had control of the LS-PrePost software, as well as running calculations in LS-DYNA software and reading the results of a numerical modal analysis from the output file (Fig. 8).

\section{Sensitivity analysis}

The optimization method has been applied to tune eigenfrequencies of the continuous miner boom to the excitation force spectrum. The numerical model consists of 56716 shell elements of which 16674 are rigid and 40044 are deformable. The considered design variables represent the thickness of the continuous miner boom components and are shown in Fig. 9. They have a crucial influence on the total mass of the boom and the considered eigenfrequencies.

At the beginning of the analysis, all elements have been assumed to have a thickness of $0.05 \mathrm{~m}$. The sensitivity analysis was done by changing one design variable linearly and calculating the response of the model. The following graph shows the sensitivity of the total mass and fifth mode shape eigenfrequency to particular design variables.

Assuming a thickness of the cutter boom arm of $x=0.05 \mathrm{~m}$, the fifth eigenfrequency was $9.9 \mathrm{~Hz}$. Figure 10 shows that this is very close to the frequency of excitation resulting from the excavation of the material, that is, $9.0 \mathrm{~Hz}$. In modal analysis, by changing the parameter only in the range of $0.01-0.1 \mathrm{~m}$, the sensitivity of the individual variables was obtained. The change of the second eigenfrequency in function of the variable $x$ is shown in the Fig. 10. When there is a simultaneous change in the body thickness, one can observe a change of the total weight of the cutter boom arm, which is also shown in the Fig. 10. 


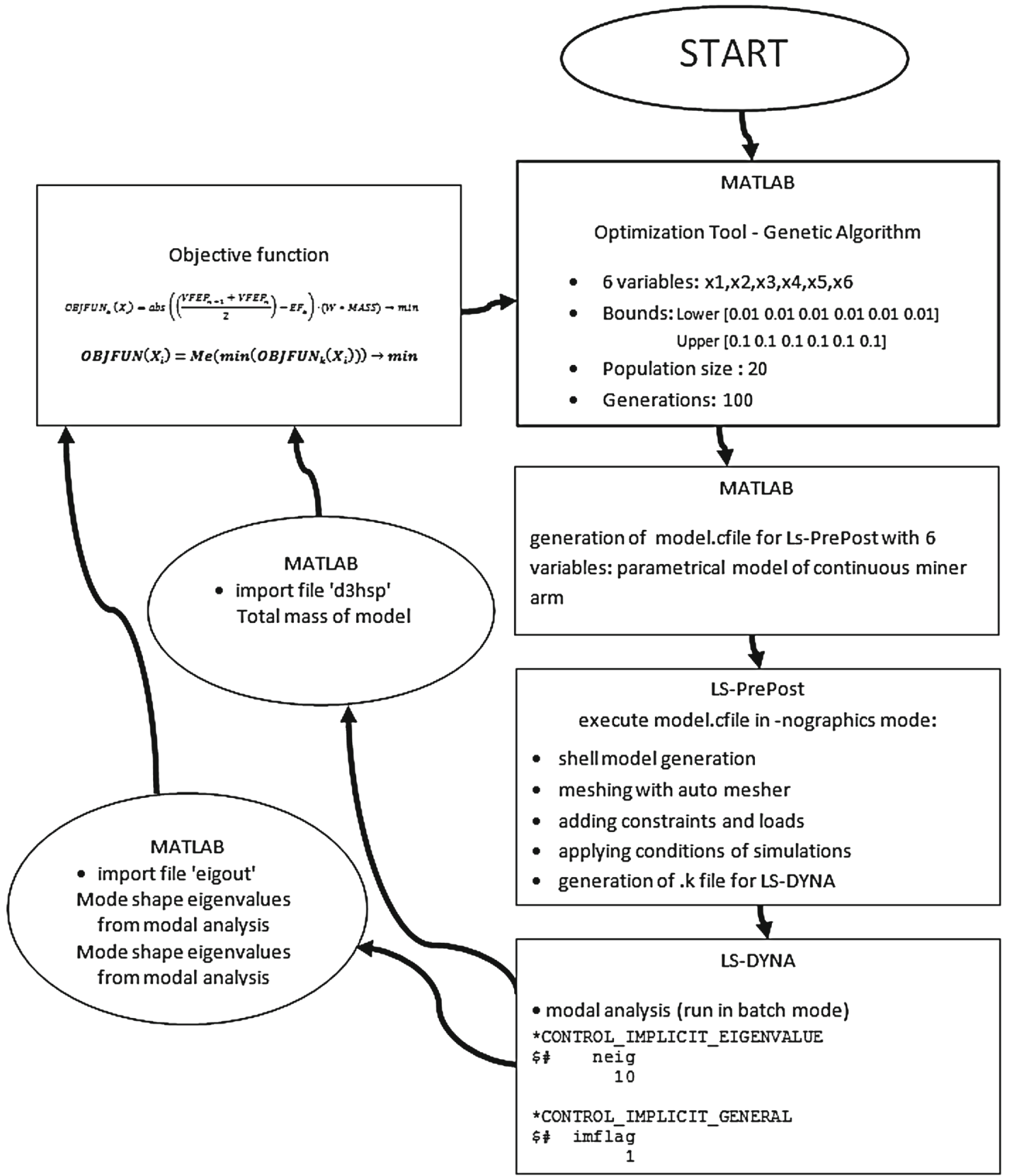

Fig. 8 Methodology of applied optimization process

Variables $x 5$ and $x 6$ have the most important influence on the fifth eigenfrequency, but a very small influence of variables $x 1$ and $x 3$ is observed. In the case of the total weight of the boom cutter arm, variables $x 5$ and $x 6$ have the major impact, while variables $x 1$ and $x 2$ have the smallest impact.

In the optimization issue, with the aim of reducing the total mass of the system and obtaining the frequency within a certain gap, it is difficult to find a simple correlation between the values of design variables.

The increasing trend in both mass and eigenfrequency indicates that these parameters have the strongest influence on the geometrical stiffness matrix. The influence of particular design variables on other mode shapes is presented in the Fig. 11. 


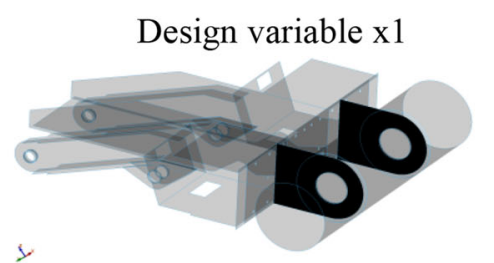

$y$

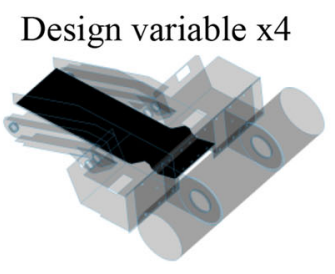

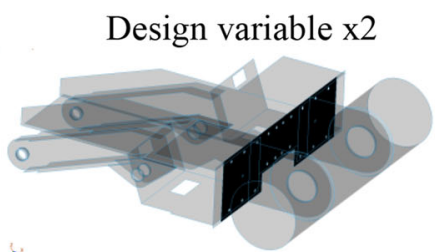

Design variable $\mathrm{x} 5$

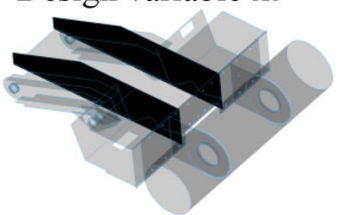

Design variable $\mathrm{x} 3$

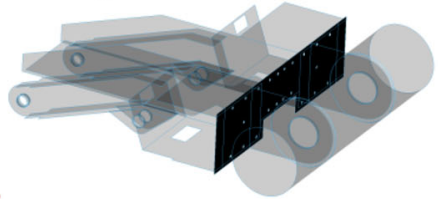

Design variable $\mathrm{x} 6$

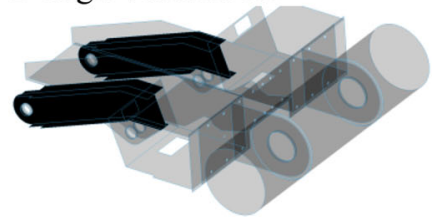

Fig. 9 Visualization of selected design variables
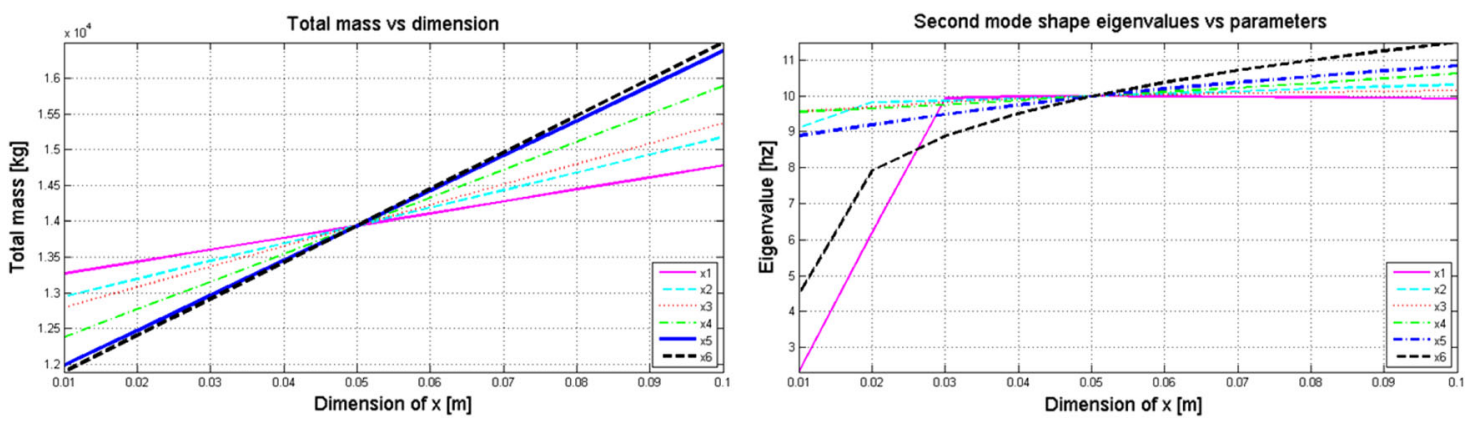

Fig. 10 Sensitivity of total mass and second mode shape eigenvalues with respect to design variables

\section{Optimization process and results}

The optimization process has been performed with the methodology presented in Fig. 8. The design variables considered in the optimization process could be changed in the range from 0.01 to $0.1 \mathrm{~m}$. The optimization of the cutter boom was done for cases with and without the mass factor. The optimization was done for these cases with the same initial conditions as in the simply supported beam test. In both cases, the population size was 20 individuals, and the stopping criterion was set to 100 generations (Figs. 12, 13, 14, 15).

The algorithm was stopped in the 51st generation in the case with the mass factor and in the 60th in the case without it, as there was no change in the average fines value from $10 \mathrm{e}^{-6}$.

The significant difference in objective function variants is visible in the second mode shape eigenfrequency of the cutter boom. The final value of the eigenfrequency with the applied mass factor is $5.9 \mathrm{~Hz}$. When the mass factor is neglected, the second mode shape eigenfrequency is $10.35 \mathrm{~Hz}$. Analyzing the FFT of the resultant excitation torque, a lower value of the second eigenfrequency can result in a higher risk of resonance (Fig. 16).

According to the final result of the optimization process, when the mass factor is neglected, the total mass of the cutter boom is $1.472 \mathrm{e}^{4} \mathrm{~kg}$. Implementing the mass factor in the objective function results in a decrease of the mass to $1.378 \mathrm{e}^{4} \mathrm{~kg}$. As can be seen from the sensitivity analysis shown in Fig. 10, design variables 4, 5, and 6 have the greatest influence on the total mass (Fig. 17).

As can be seen in Fig. 18, variables $x 5$ and $x 6$ had the greatest influence on the optimization results. The genetic algorithm found minima for both the objective functions analyzed (Fig. 19).

\section{Dynamics of continuous miner's boom}

The interaction between the cutting tools and the longwall was developed by using two forces. The first cutting force Pd is changed from the minimal to the maximal value during rock penetration by the cutting tool, while 

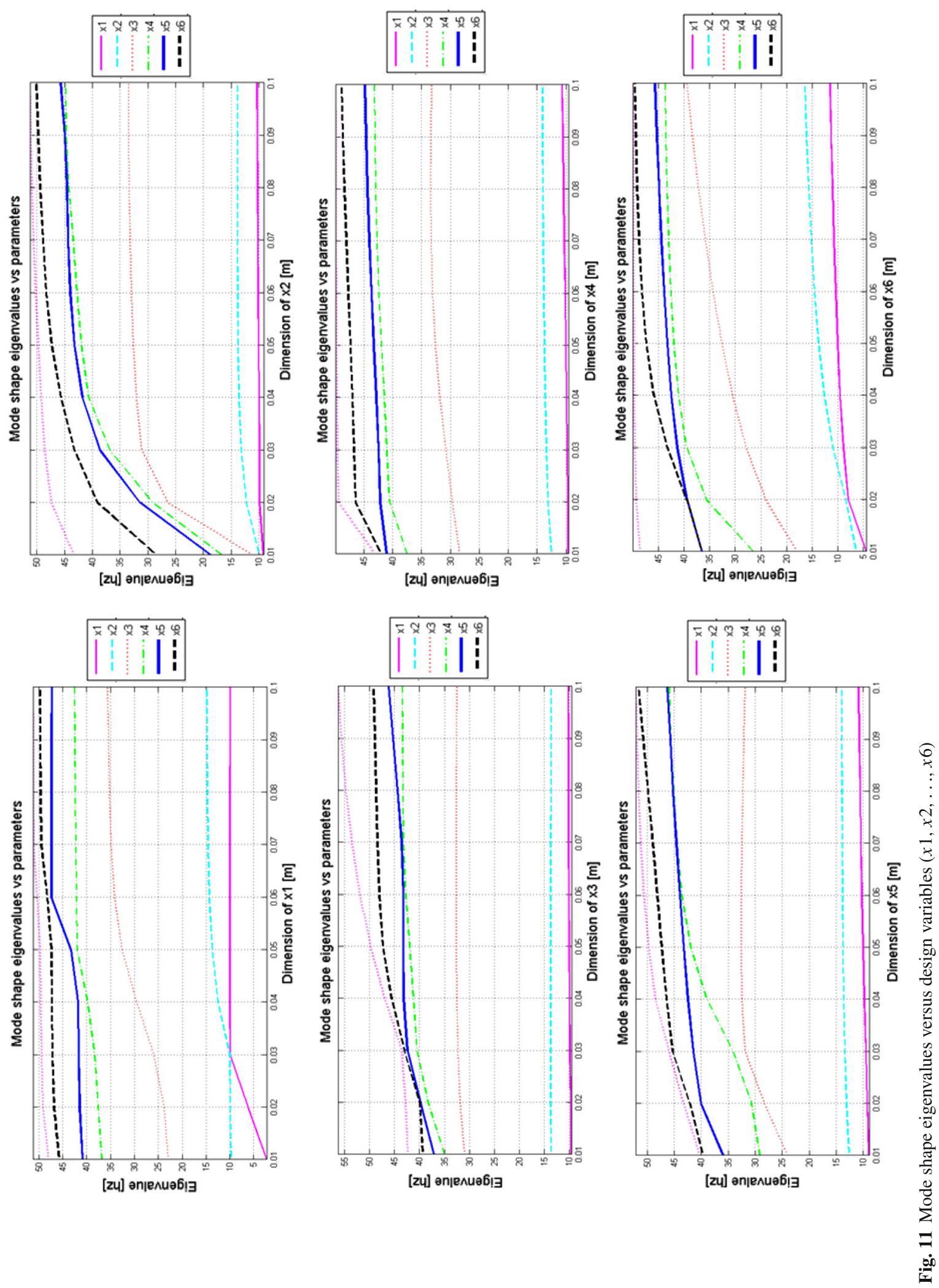
Objective function worst and mean values vs optimization process
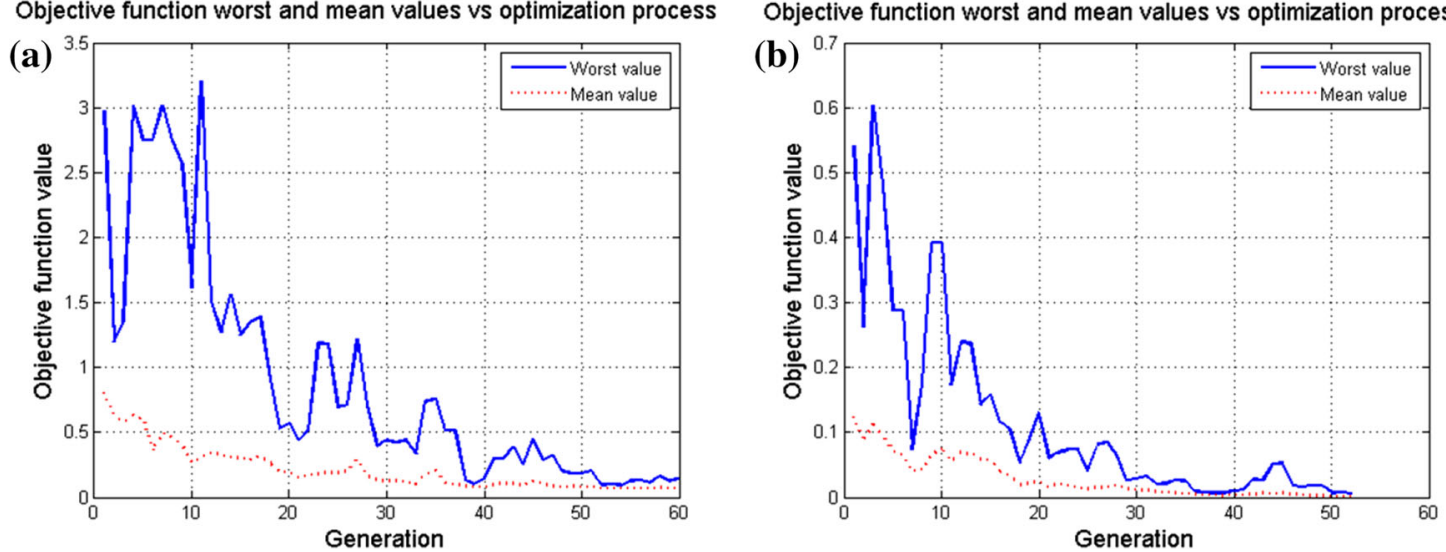

Fig. 12 The worst and mean values of the objective function: a without mass factor; $\mathbf{b}$ with mass factor
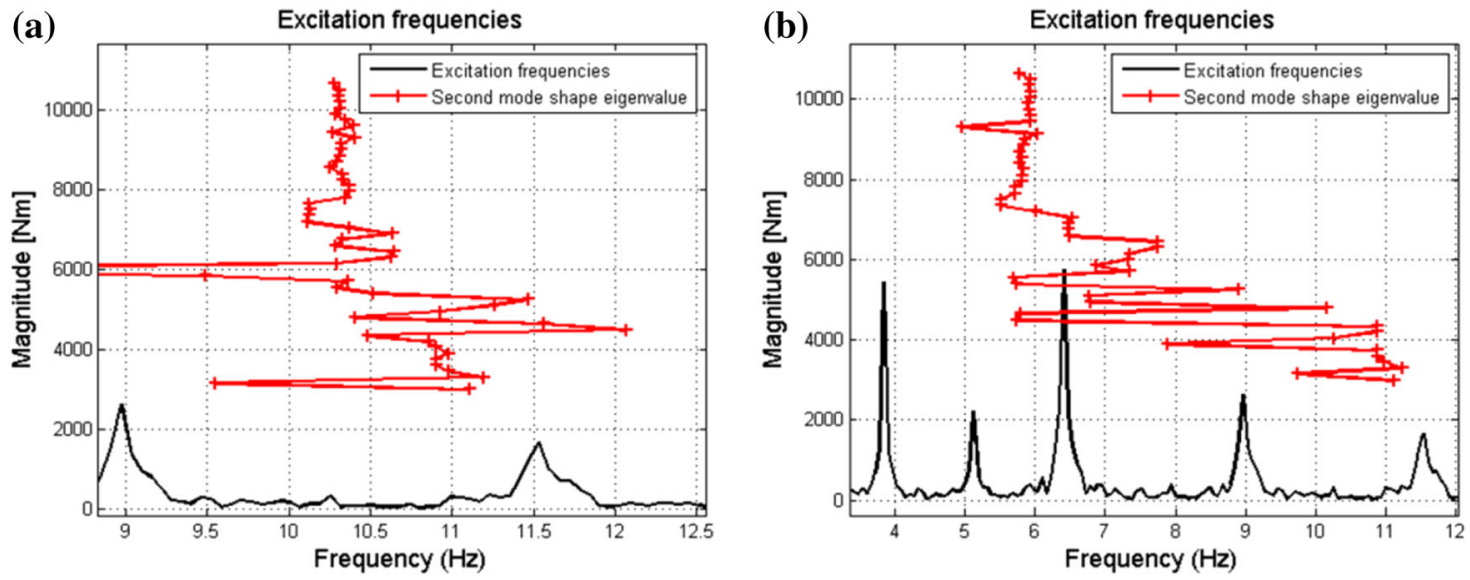

Fig. 13 The second mode shape eigenfrequency: a without mass factor; $\mathbf{b}$ with mass factor

(a)

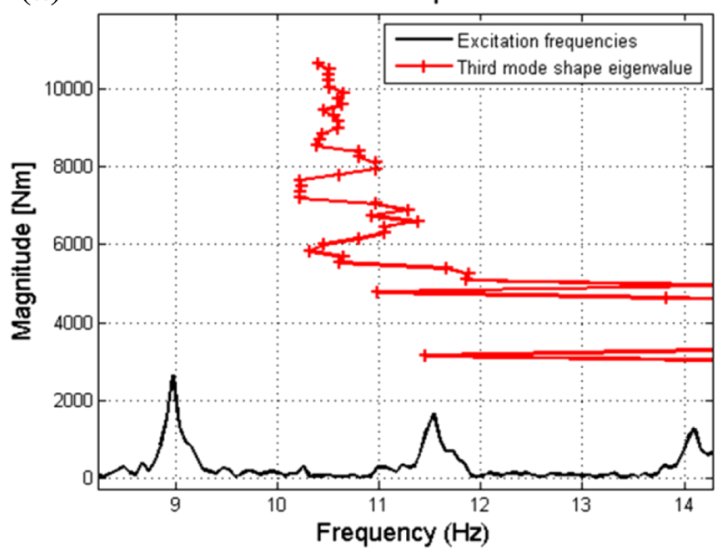

(b)

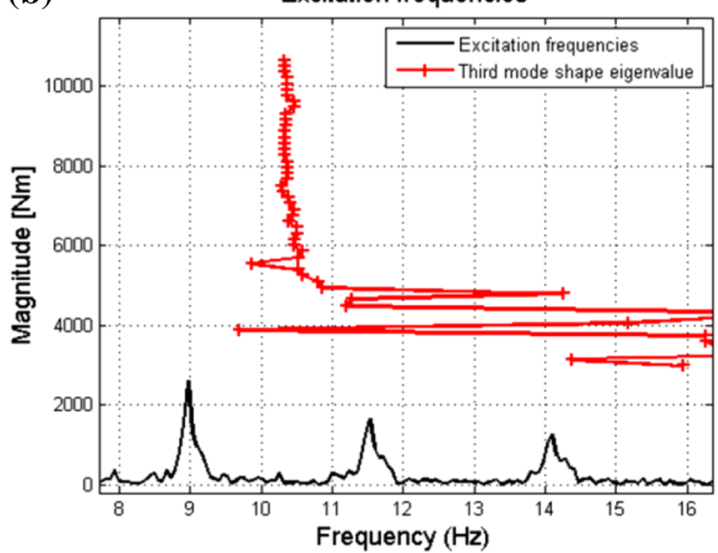

Fig. 14 The third mode shape eigenfrequency: a without mass factor; $\mathbf{b}$ with mass factor

the second contact force Pd has an inverted distribution. A linear change of the forces was assumed in the simulation. Figure 20 presents the forces acting on the cutting drum.

The particular forces from individual tools have been summated and recalculated to give the resultant torque. The gaps between tools produce different excitation frequencies. This was the basis for determining 

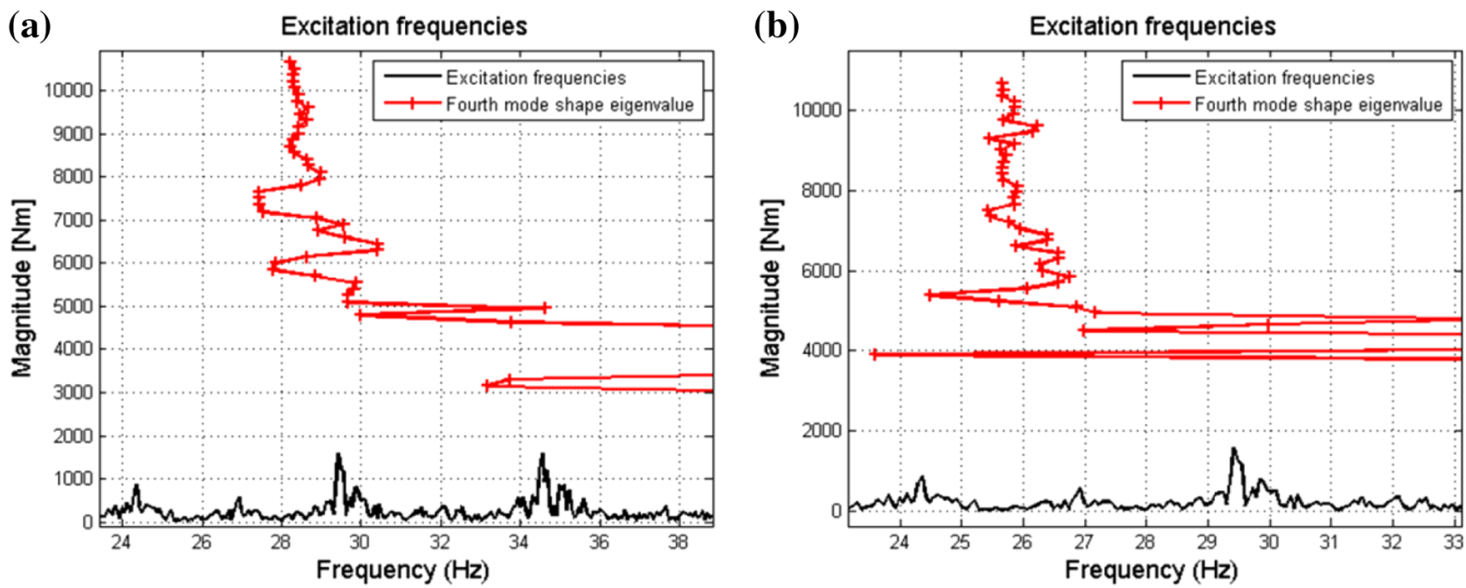

Fig. 15 The fourth mode shape eigenfrequency: a without mass factor; $\mathbf{b}$ with mass factor
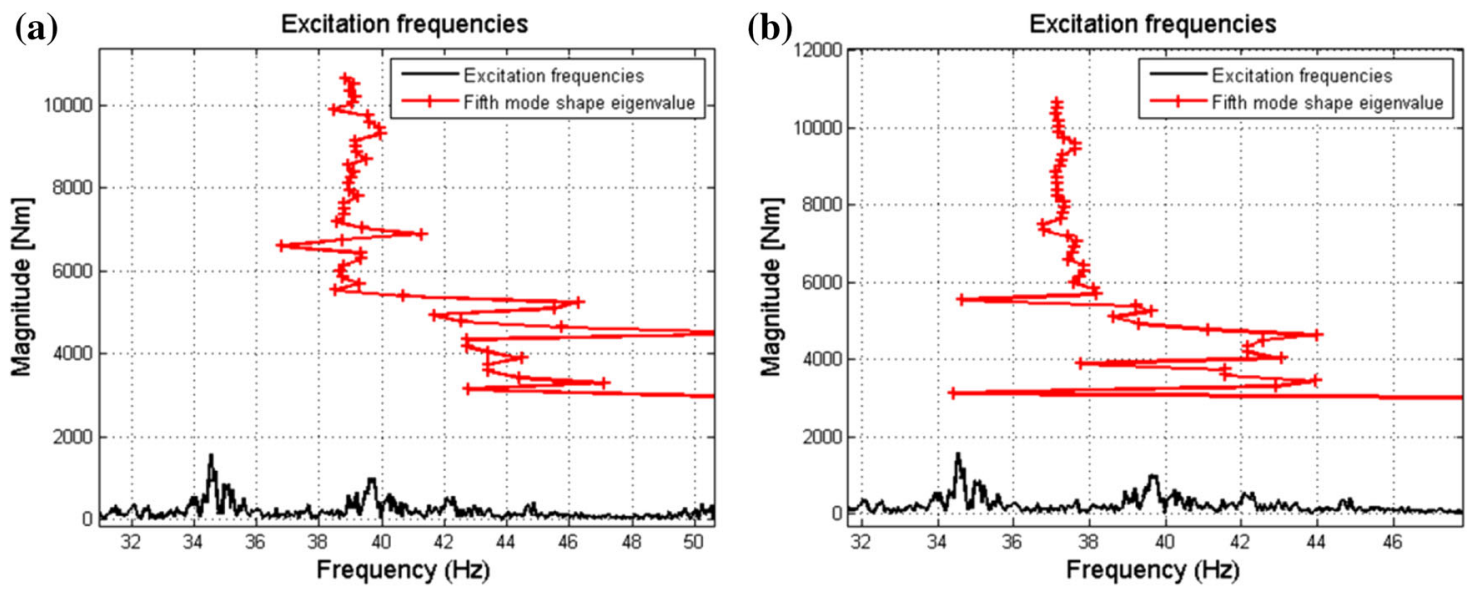

Fig. 16 The fifth mode shape eigenfrequency: a without mass factor; $\mathbf{b}$ with mass factor
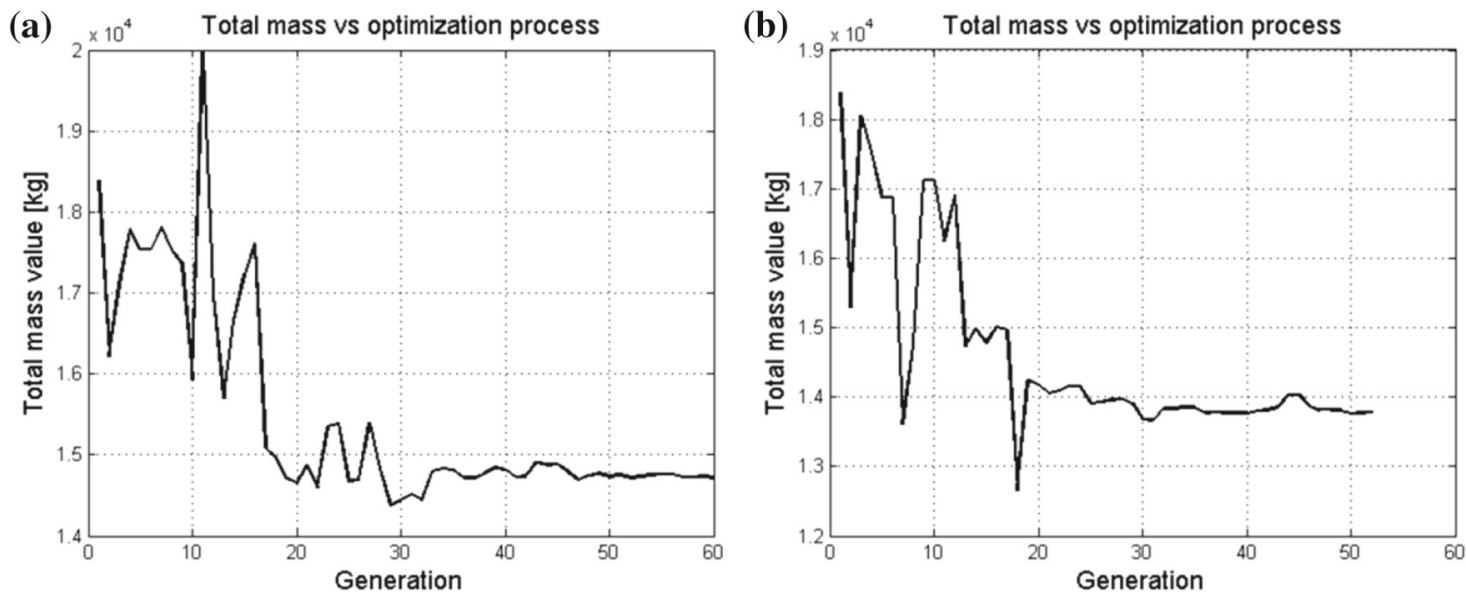

Fig. 17 Total mass vs optimization process: a without mass factor; $\mathbf{b}$ with mass factor

the initial condition for full explicit transient dynamic analysis in the LS-DYNA solver. The values of the design variables after the optimization process (case with mass factor) were applied to the numerical model.

For further analysis, four points were selected, and their locations are shown in Fig. 21. These points represent the nodes of the second, third, fourth, and fifth mode shapes. 

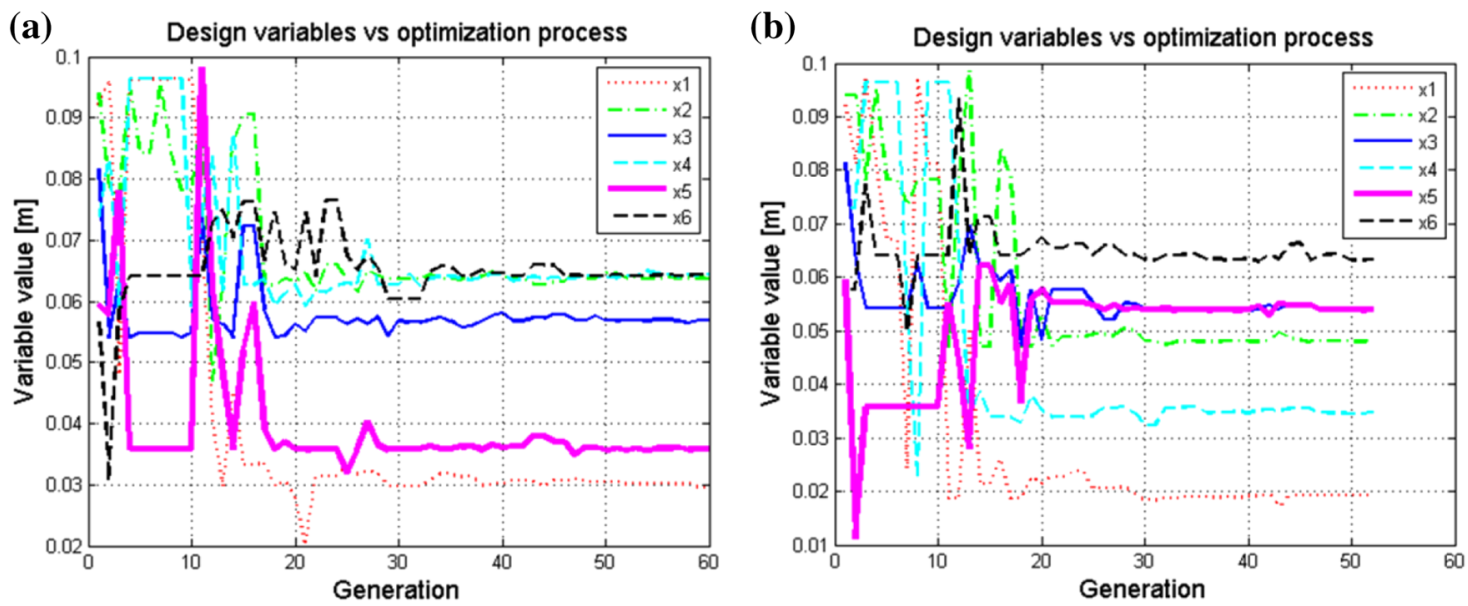

Fig. 18 Results of optimization process: a without mass factor; $\mathbf{b}$ with mass factor

(a) Objective function vs generation

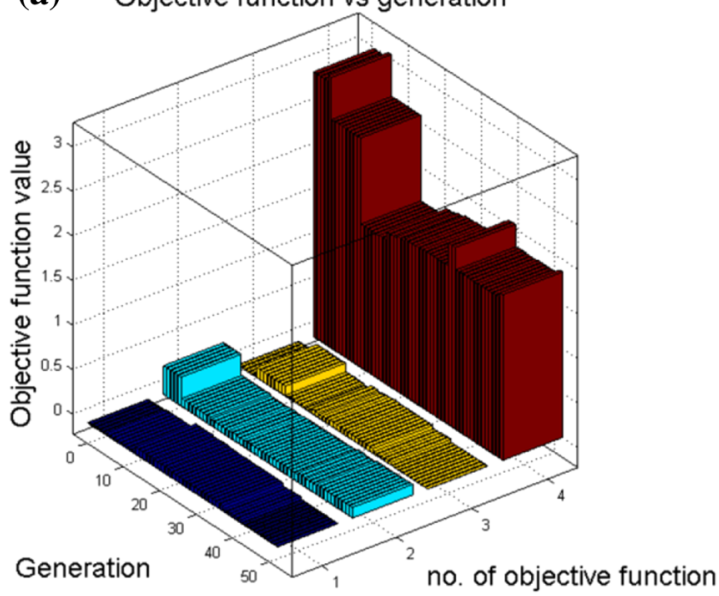

(b)

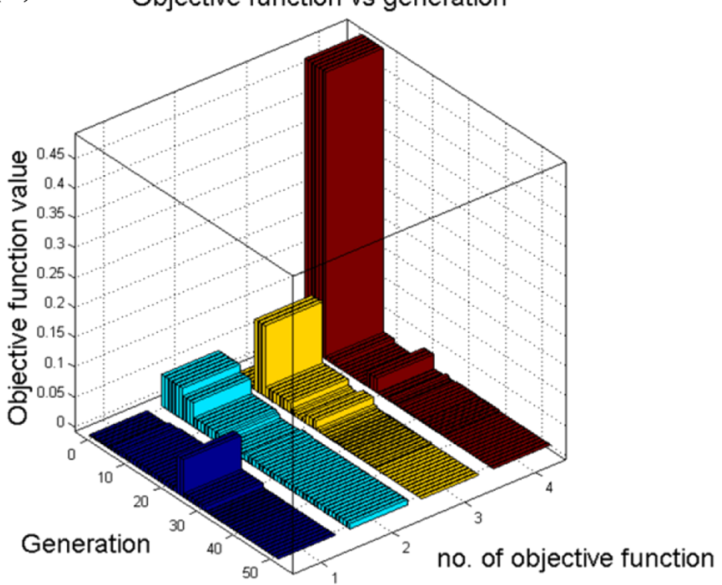

Fig. 19 Objective functions: a without mass factor; $\mathbf{b}$ with mass factor

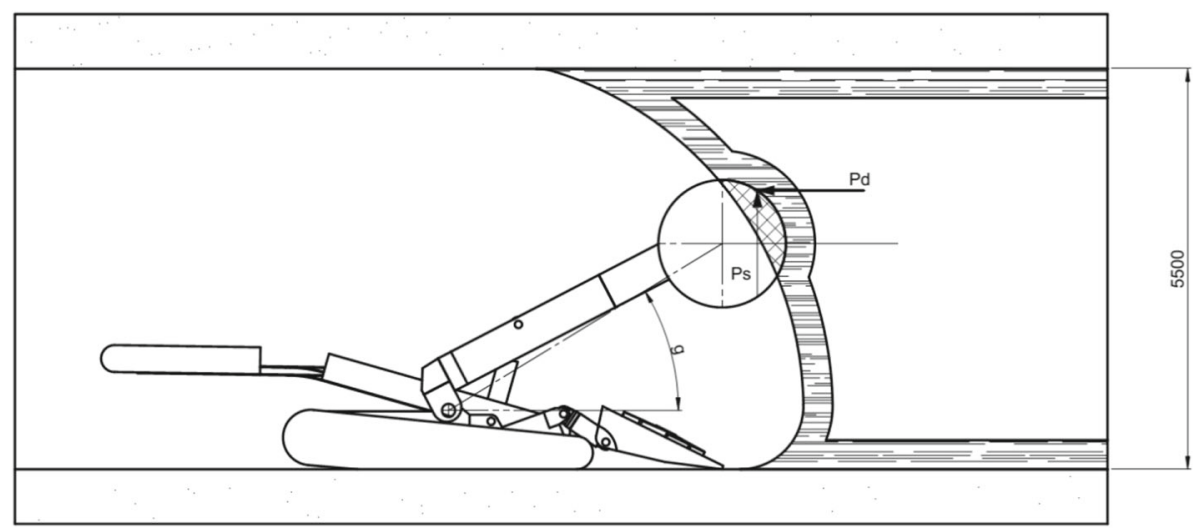

Fig. 20 The cutting process loads

The signal charts (Fig. 22) show that time points increased the resultant acceleration of the structure. The first time range of increased acceleration is from the start to $0.9 \mathrm{~s}$ and is related to an angular velocity equal to approximately $1.5 \mathrm{rad} / \mathrm{s}$. The second time range is from 3.5 to $4.5 \mathrm{~s}$ and is related to an angular velocity of 


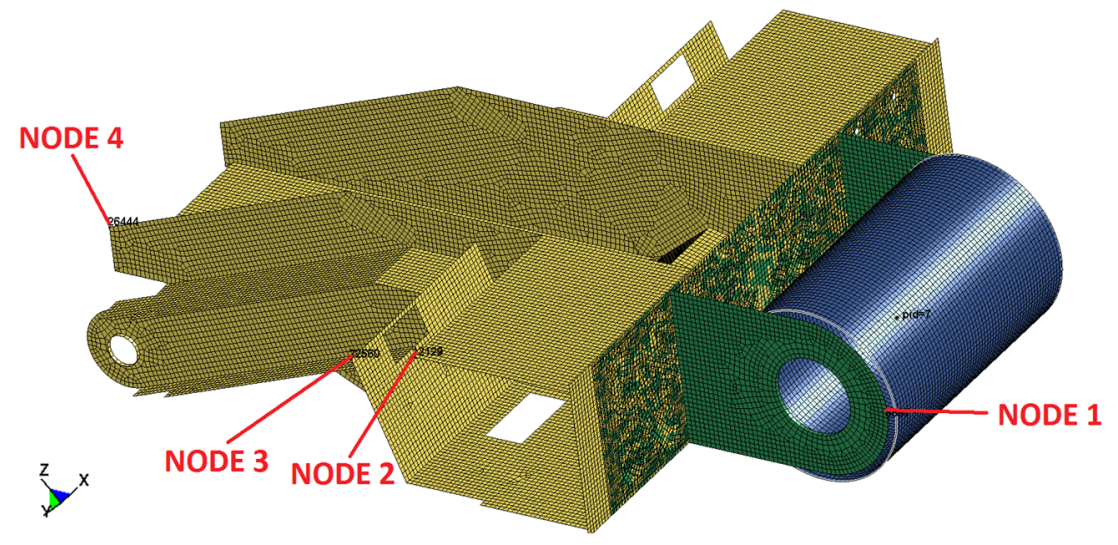

Fig. 21 The nodes selected to acquire acceleration

(a)

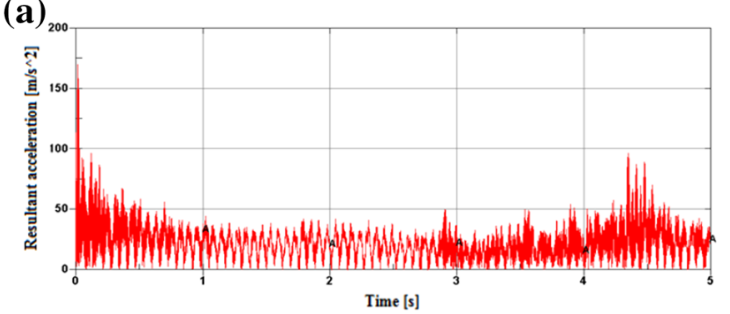

(c) ${ }_{250}$

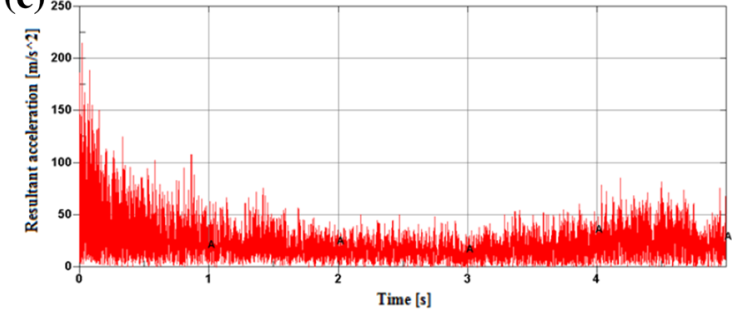

(b)

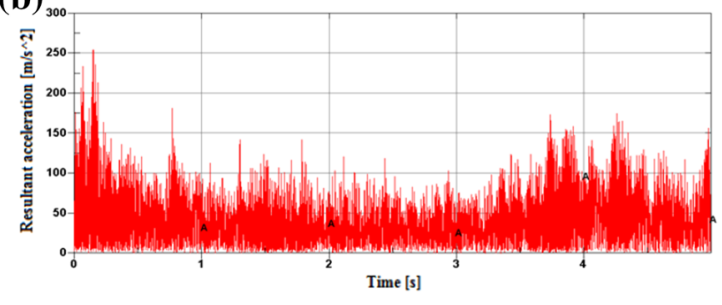

(d)

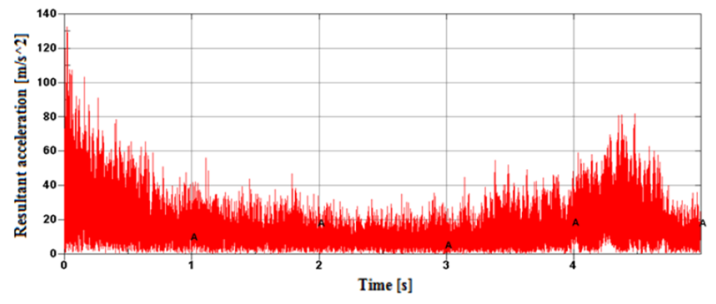

Fig. 22 The time-dependent resultant acceleration result for: a node 1; b node 2; $\mathbf{c}$ node 3; $\mathbf{d}$ node 4
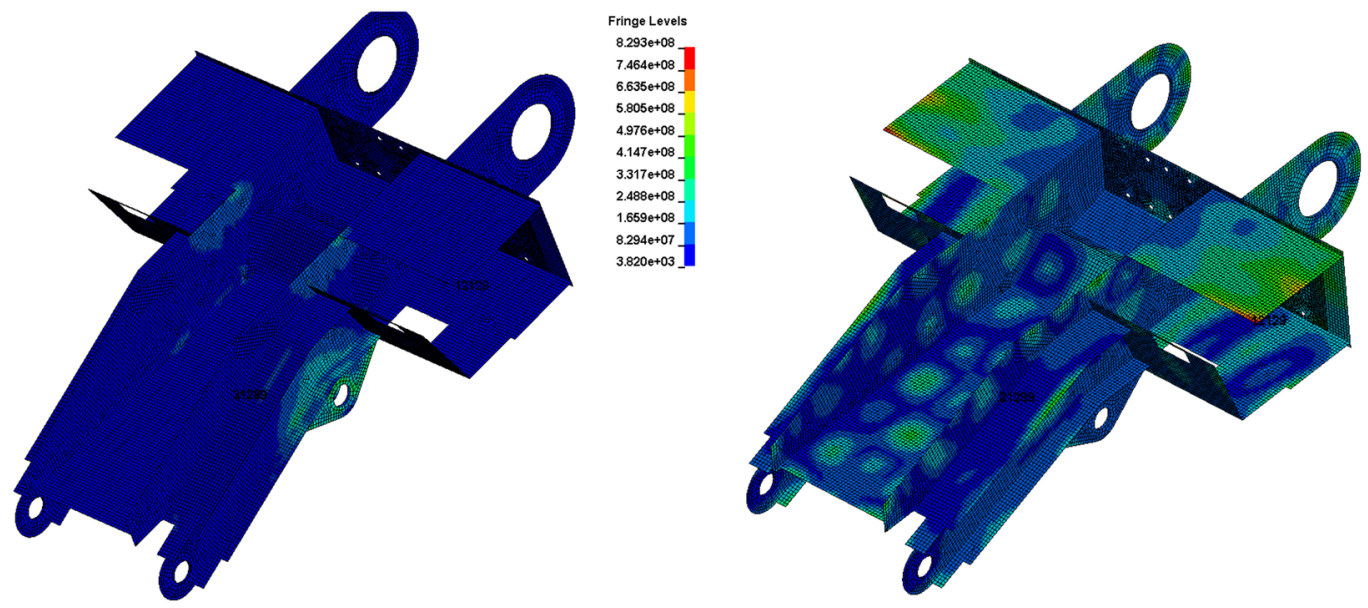

Fringe Levels

1.162e+02

$1.046 \mathrm{e}+02$

.

-

59240

$4.665 \mathrm{e}+01$

$3.506+01$

$1.187 \mathrm{e}+01$

2.835e-01]

Fig. 23 The resultant von Mises stress (left) and acceleration (right) distribution for time $4.42 \mathrm{~s}$

5.8 to $9.1 \mathrm{rad} / \mathrm{s}$. The maximum resultant accelerations occur at $4.42 \mathrm{~s}$, and the resultant von Mises stress and acceleration maps for this time are shown in Fig. 23.

The increased resultant acceleration was related to the transition between the eigenfrequencies of the systems as the angular velocity of the cutting head increased. It was noticed that there was no danger of 
resonance in normal cycled work at a rotational speed of $5.24 \mathrm{rad} / \mathrm{s}$. The related excitation frequencies (Fig. 1) of this rational speed were used to perform optimization according to the proposed objective function.

\section{Conclusions}

The presented way of modeling a complex machinery system and the algorithms for solving the problems of dynamics are of a general nature. This enables the designer to take into account any kind of physical relation in kinematic pairs and any state of load variation in the simulation. The paper also presents the application of the elaborated methodology for the optimization of modal parameters of roadheader structures. The objective function is designed properly, taking into account the results which were obtained. The total mass of the cutter boom decreased to 13.78 tons, and the highest distance of the fifth eigenmode from the peaks referred to the spectrum presented in Fig. 1 was achieved. In earlier attempts at optimization, in the objective function, there was a lack of mass influence, and the modeled total mass after optimization was about 14.75 tons. In the optimization process, there was an assumption that design variables $x 1$ to $x 6$ could change from 0.01 to $0.1 \mathrm{~m}$, without checking whether the strength of the cutter boom was sufficient. In the next step, the optimization process should take into consideration the stress values of the considered mechanical system. This additional issue will increase the calculation time but also leads to more accurate results. The chosen design variables are the thicknesses of specified parts. They are good to show the methodology of optimization. The number of design variables in the parametric model can increase, and the character of design variables such as characteristic lengths and distances can change.

Acknowledgments The authors gratefully acknowledge funding by the National Science Centre, Poland, under grants 3383/B/ T02/2011/40.

Open Access This article is distributed under the terms of the Creative Commons Attribution License which permits any use, distribution, and reproduction in any medium, provided the original author(s) and the source are credited.

\section{References}

1. Dresig, H., Holzweissig, F.: Dynamics of Machinery Theory and Applications. Springer, New York (2010)

2. Świtoński, E., Mężyk, A.: Selection of optimum dynamic features for mechatronic drive systems. Autom. Constr. 17(3), 251-256 (2008)

3. Vas, P.: Electrical Machines and Drives. A Space Theory Approach. Oxford University Press, Oxford (1992)

4. Haftka, R.T., Gürdal, Z., Kamat, M.P.: Elements of Structural Optimization. Kluwer, New York (1990)

5. Bo,Yu.: Numerical simulation of continuous miner rock cutting process. PhD Dissertation, University of West Virginia (2005)

6. Sibielak, M., Raczka, W., Konieczny, J.: Modified clipped-LQR method for semi-active vibration reduction systems with hysteresis. Solid State Phenom. 177, 10-22 (2011)

7. Haug, E.J., Choi, K.K., Komkov, V.: Design Sensitivity Analysis of Structural Systems. Academic Press, New York (1986)

8. Yoo Hong, H., Cho Jung, E., Chung, J.: Modal analysis and shape optimization of rotating cantilever beams. J. Sound Vib. 290, 223-241 (2006)

9. Roy, R., Hinduja, S., Teti, R.: Recent advances in engineering design optimisation: challenges and future trends. CIRP Ann. Manuf. Technol. 57, 697-715 (2008)

10. Wagner, A., Spellsberg-Korspeter, G., Hagedorn, P.: Structural optimization of an asymmetric automotive brake disc with cooling channels to avoid squeal. J. Sound Vib. 333, 1888-1898 (2014)

11. Deibel, K., Wegener, K.: Methodology for shape optimization of ultrasonic amplifier using genetic algorithms and simplex method. J. Manuf. Syst. 32, 523-528 (2013)

12. Bagheri, M., Jafari, A., Sadeghifar, M.: A genetic algorithm optimization of ring-stiffened cylindrical shells for axial and radial buckling loads. Arch. Appl. Mech. 81, 1639-1649 (2011)

13. Tsai, T.D., Cheng, C.C.: Structural design for desired eigenfrequencies and mode shapes using topology optimization. Struct. Multidisc. Optim. 47, 673-686 (2013)

14. Meske, R., Lauber, B., Schnack, E.: A new optimality criteria method for shape optimization of natural frequency problems. Struct. Multidisc. Optim. 31, 295-310 (2006)

15. Basques, J.P.: Multi-material topology optimization of laminated composite beams with eigenfrequency constraints. Compos. Stuct. 111, 45-55 (2014)

16. Messac, A., Ismail-Yahaya, A., Mattson, C.A.: The normalized normal constraint method for generating the Pareto frontier. Struct. Multidisc. Optim. 25, 86-98 (2003)

17. Ostwald, M., Rodak, M.: Multicriteria optimization of cold-formed thin-walled beams with generalized open shape under different loads. Thin Walled Struct. 65, 26-33 (2013)

18. Zółkiewski, S.: Dynamic flexibility of the supported-clamped beam in transportation. J. Vibroengineering 13(4), 810$816(2011)$ 
19. Katsikadelis, J.T., Babouskos, N.G.: Stiffness and buckling optimization of thin plates with BEM. Arch. Appl. Mech. 82, 1403-1422 (2012)

20. Noori, B., Farshidianfar, A.: Optimum design of dynamic vibration absorbers for a beam based on $\mathrm{H} \infty$ and $\mathrm{H}_{2}$ optimization. Arch. Appl. Mech. 83, 1773-1787 (2013)

21. Farkas, L., Donders, S., Schildermans, D., Moens, D., Vandepitte, D.: Optimisation study of a vehicle bumper subsystem with fuzzy parameters. Proceedings of ISMA 2010 including USD2010

22. Duddeck, F., Zimmer, H.: New achievements on implicit parameterization techniques for combined shape and topology optimization for crashworthiness based on SFE CONCEPT. Shape and Technology Optimization for Crashworthiness, ICRASH2012

23. Schwanitz, P., Sankarasubramanian, H., Werner, W.J.S., Göhlich, D., Chawla, A., Mukherjee, S.: Methodology for multiparameter optimization during the concept phase for crash relevant vehicle structures. 9th Weimar Optimization and Stochastic Days (2012) 